\title{
Challenges and Problems of Overseas Chinese Students Socializing into International Academic Settings
}

\author{
Yun Tao \\ Southeast University \\ Foreign Languages School \\ Nanjing, China \\ e-mail:taoyun_seu@yahoo.com
}

\author{
Renjie \\ Hu Southeast University \\ Electrical and Electronics Experiment Center \\ Nanjing, China \\ e-mail: hurenjie@seu.edu.cn
}

\begin{abstract}
This article explores challenges and problems that overseas Chinese students are encountered: the first language (L1) cognitive functioning norms which differ from those of the second language (L2) are hypothesized to significantly affect their $L 2$ socialization in academic settings. Theories on $L 2$ socialization are drawn to analyze factors, namely, negotiating competence, identities and power relations that hinder students from successfully being involved into alien discourse communities. The in-class observations at University of British Columbia and six-year-English-teaching-abroad experience for both overseas Chinese students and international students were collected as research data to extend an understanding of L2 socialization across post-secondary settings. The study indicates that L2 socialization is not a simply one-way assimilation or acculturation but a complex dynamic process of reconstructing personal agency and competence to be recognized as legitimate and competent members of the globally internationalized academic circumstances.
\end{abstract}

Keywords-overseas Chinese students; second language socialization;legitimate academic context;identity;

\section{INTRODUCTION}

The $20^{\text {th }}$ and 21th centuries have witnessed the everincreasing flow of Chinese students to study abroad. The 2010 figure [1] indicates that four high-ranking countries are America, Great Britain, Australia and Canada which respectively amount to $33.86 \%, 16.14 \%, 12.72 \%$ and $12.68 \%$ of total Chinese overseas students. However, since students' bilingual cognitive functioning norms of native language (L1) are not the same and hypothesized to affect their second language socialization (SLS) significantly [2], factors such as negotiating competence, identities, and power relations to be recognized as a legitimate and competent member of the academic community-of-practice (COP) are the primary challenges and problems for international students to confront. The goal of this paper is (1) to provide a brief review of research on L2 socialization, (2) to illustrate the significance of socializing Chinese overseas students into international academic context (3) elaborate current theoretical and empirical conceptualizations of it, and (3) to analyze factors that restrict Chinese students from socializing themselves in new discourse communities.

\section{DEFINITION OF THE ACADEMIC SOCIALIZATION IN L2}

"Academic discourse socialization, in short, views learning as developing the capability to participate in new discourse communities as a result of social interaction and cognitive experience. It also involves developing one's voice, identity, and agency in a new language/culture” [3]. In other words, the purpose of academic discourse socialization is to get novices involved into the "new discourse community" where they can be apprenticed to develop their own "voice, identity and agency". Comparing with the earlier research which focus on L1 language learners' learning academic literacy especially their composition skills, the currently emerging area has started to lay emphasis on "non-traditional" students regarding how to "prepare L2 students academically in English as second language (ESL) or English for academic purposes (EAP) programs and discourses[4]. How to socialize L2 non-native English speakers into the academic presentation discourse has aroused much interest to the recent researchers and EFL instructors.

\section{SigNifiCANCE OF SOCIALIZING NON-NATIVE ENGLISH SPEAKERS INTO ACADEMIC PRESENTATION DISCOURSE}

"Given the growing population of linguistically and culturally diverse students in North American colleges and universities, understanding how these students participate in their new academic communities and acquire academic discourses in their second language (L2) has become critical” [5].

The interest in this study lies in the uprising outflow trend of Chinese students who pursue their study abroad and my own academic background as both an English foreign language (EFL) instructor and a facilitator of international bilingual or multilingual university students who frequently visit my working university in China. This attracts me to better understand the discursive practices and requirements of L2S. Besides as a master degree student at UBC between 2007 and 2009, I have experienced a complex process of socializing myself in the academic L2 register. And I am convinced that the research can enlighten both those students like me as well as international student instructors who are interested in socializing students into academic programs and discourse to fulfill their academic education at foreign countries. 
IV. CURRENT ISSUES ON SOCIALIZATION OF ACADEMIC DISCOURSE

\section{A. Duff's five issues on academic discourse socialization}

Duff [6] identifies five issues associated with academic discourse socialization especially oral presentation socialization in L2 contexts, which need greater problematisation. Firstly, students being socialized into new, multimodal, intertextual, heteroglossic literacies and repartee find themselves more difficult to comprehend or engage in than strictly 'academic' language and topics due to their low proficiency in the classroom language or lack of the necessary cultural background knowledge. Also L2S instructors may not offer the sufficient scaffolding, modeling or feedback to the L2 learners who expect to be fully accommodated and apprenticed within their new communities by their native instructors with respect to student legitimacy. Thirdly, the issue encompasses the crucial attention to oral academic discourse since the oral presentation can be "socially, cognitively, and discursively complex and variable" in a wider context of a classroom, a thesis defense theatre or other academia such as "negotiating office hours visits or assignments, sending requests to a potential research supervisors" etc. The ecology of tasks or assignments should also be concerned since the instructors sometimes cannot be aware of the "these behind-the-scenes aspects of task enactment, students' misunderstandings or misgivings, the teachers' (or researchers' and testers') own unclear instructions, or of students' attempts to subvert the instructors' guidelines or specifications in various ways based on their own sense of agency, entitlement, or even desperation”. The final section addresses the 'afterlife' of socialization or "how the sorts of cumulative socialization experiences" affect subsequent socialization. Since socialization is both lifelong and life wide [7] and each new context "may have different specifications for appropriate forms of discourse", the instructors of L2S should adapt their models to match the ever-changing settings and novice practitioner's needs.

\section{B. Morita's legitimate peripheral participation issue}

Morita [8] reports from a COP perspective on a qualitative multiple case studies to explore how " $\mathrm{L} 2$ learners negotiated their participation and membership in their new L2 classroom communities, particularly in open-ended class discussions". She assumes that L2 learners' socialization is a process called "legitimate peripheral participation (LPP)" during which conflicts, struggles and negotiation between differing viewpoints maybe arise. The students may employ various strategies or their personal agencies to experience profound transformation in order to construct an identity as a "competent and valued members". They may actively either appeal support from the instructors and their more experienced peers or alienate themselves as the outsiders and remain at the periphery of the classroom context. To sum up, the crucial issue for instructors is to prompt students to exercise their agency to position themselves in the proper legitimate classroom communities so that they would not feel peripheral or marginalized from the mainstream classroom context.

\section{Zappa-Hollman's interplay between internal and external factors.}

Zappa-Hollman [9] reveals that "oral discourse contributes significantly to their academic socialization” by conducting research on six non-native graduate students through their "engagement in an oral activity, the academic presentation (AP)". She stresses on some affective variables such as the "interplay between internal (from the individuals) and external (from the social contexts)" factors, which may hinder or restrict students' involvement or participation of oral presentation. The external factors, which differ from the traditional focus on the traditionally recognized cognitive and psycholinguistic difficulties faced by the students, Zappa-Hollman assumes that students' background and their past experiences with the activity in their respective former and current socio-cultural contexts also play a crucial role in L2S. The results show that APs, as a "central activity" in the academic discourses, is regarded as being "daunting" if there was a clear "discrepancy between their home-country notions" and the accepted or shared values fostered in the host countries. This clash may evoke their emotional resistance or at least their anxiety and nervousness which need time and efforts to deal with.

\section{OBSERVATION AND REFLECTION ON SOCIALIZATION of ACADEMIC PRESENTATION DisCOURSE}

The above-mentioned theories suggest that L2 socialization in the oral academic discourses is twodirectional, unpredictable and less linear. It is not a simple one-way assimilation or acculturation of the relatively stable academic communities, but instead a bi-directional adaptation of both L2 learners and agencies while reconstructing a dynamical situated academic community with the situated rules and conventions. Namely, this discourse community is "open, conflictual and dynamic [10].

\section{A. The external factors function well only if the internal factors really exert efforts on them.}

The L2S studies "foreground the interplay between internal (from the individuals) and external (from the social contexts) factors that have an impact on L2S processes” [11]. However, the external factors must rest on the internal ones. The crucial factor for a successful L2S in the OAP context, to great extent, is subject to the novices' individual affective factors such as inclination to acculturating themselves into the most common practices of the academic worlds which they aspire to belong, their reaction and action to articulate, negotiate to be legitimate community members and their goals and orientation to acquire linguistic and socio-cultural knowledge holistically. Based on 11 post-graduate students during my study with them and seven undergraduate students individually interviewed by me, only three of them actively prefer to avail myself of every chance at the class to 
contribute to the peer discussion or oral presentation only because these three graduate students are planning to resume English teaching as their professions after completion of their post-graduate education in English speaking countries. They strongly assert that the Oral APs play the crucial role to position myself in the accepted communities to articulate their opinion and learn to negotiate their identities. Most important of all is that this competence is what they should be possessed with for better preparing themselves as future professionals. Thus, they are more readily inclined to participate in class and perform their academic program. Conversely, seven overseas Chinese engineering students and eight post-graduate students complained of too much class participation, smallgroup work, oral presentations, debates or WebCT postings which are regarded as being "daunting" for them at their alien host country namely Canada. They all agreed to the significance of OAP for them, but mentally they resist this kind of academic socialization and as a result three among eight post-graduate students whose majors are English as second language quit the courses associated with L2S which need plenty of oral presentation. They alternated the courses The internal mental factor hinders these L2 learners from reconstructing their identities and positionality in the AOP context albeit they are equipped with the optimal external factors like very nice and prestigious instructor, favorable classroom arrangement and very supportive academic COP etc.

\section{B. Extemporaneous talk, the more salient challenge to non-native English speakers, is sometimes affected by "face-saving" issues}

They may feel frustrated if their extemporaneous talk displays unsuccessful. They may feel losing their face before their native peer. If they could not speak smartly, they prefer to remain reticent rather than speaking "nonsense". But another perplexing phenomenon is that reticent students at one class are talkative and active in another class. The observation suggested that students preferred to remain silent at the class composed of a large amount of international students from China. In contrast, the same group of students turned to be more active at a class primarily consisted of native English speakers. The silent students who are quite active at another class explain that they are quite clear about their language deficiency or other factors differing from native English speakers. But they transferred their disadvantages as advantages if they noticed that native speakers expressed their admiration for their courage to speak before them. The identities they have positioned themselves among native English speakers don't prevent them from feeling face-losing, but instead their particular alien background and experiences are appreciated and shared by native English speakers.

C. The turn-taking norms are hard to follow for non-native English speakers due to the cultural differences

At the outset, the non-native speakers learn to wait for their turns which differ from what they have been encouraged at their native country, namely China. In China, especially at class, those students who can promptly raise their hands and respond to the questions are highly valued and appreciated by teachers. But in Canada, students are encouraged to articulate their own opinions but meanwhile should learn to take the right turn and be attentive to others. How to balance their turns in classroom discussion really frustrates non-native L2S learners. They may behavior contradictorily. For those who view themselves as the language-deficiency, they don't feel comfortable to have their OAP before others or feel satisfied to hear their Chinese peers' oral presentation either They sometimes complain about their Chinese peers' "showing-off" at class. On the contrary, when those active Chinese students have been aware of their positioning at their Chinese peers' mind, they also feel hesitant to participate in the OAP or discussion. They have to concern their Chinese peers' feeling and don't like to "stick out" and shadow off their peers. They might fall into a "vicious circle" phenomena. Schieffelin \& Ochs propose a concept of interdependence of language and culture. Schieffelin \& Ochs [12] propose that "A defining perspective of language socialization research is the pursuit of cultural underpinnings that give meaning to the communicative interactions between expert and novice within and across contexts of situation" (p. 255). In accordance to Hofstede's Five Dimensions of Culture [13], "Individualism and Collectivism" can better interpret Chinese students' internal emotion. China belongs to the "low individualism" society where collectivism is valued and "people from birth onwards integrated into strong, cohesive in-groups, often extended families which protect them in exchange for unquestioning loyalty" [14]. Students with this strong shared standard of beliefs are inclined not to separate themselves from the collective. They should be as normal as others and pretend to be modest before peers. Saving and maintaining the face of others as well themselves are extremely important in the collectivist classroom.

\section{CONCLUSION}

Leung [15]assumes that "Language socialization is a lifelong enterprise experienced by all communities and all people. In attempting to understand how ordinary recurrent language practices enable novices to be inducted into their communities, we may better understand the universal and local interfaces between language and culture: it is surely a challenge worth undertaking." Therefore, even the oral academic presentation (OAP) in the micro-community of practice at class reveals some intangible cultural factors which Cutler [16] refers to the “core culture"---. The classroom is the micro-society for the students but it is affected by the macro-society for individual student.

With respect to second language acquisition (SLA), Hatch [17] states in her seminal paper that "one learns how to do conversation, one learns how to interact verbally, and out of this interaction syntactic structures are developed” (p. 404). Sparked by this claim, L2S instructors should examine the role of both teacher-student interactions and peer 
interactions. We should also lay stress on native-speaker versus non-native speaker (NS-NNS) interactions as well as the role of non-native speaker versus non-native speaker (NNS-NNS) interactions. And OAP and discussion at class can reveal many factors beyond the language itself which affect the success of OAP. Conversely, OAP research can provide L2S instructors with more implications to efficiently manage the classroom and explore the utmost potentials of students' language acquisition through OAP interactions.

To this end, it is perhaps desirable to conduct more qualitative studies which draw on the tradition of classroom ethnography". To explore in-depth of OAP in the nativeEnglish classroom context deserves our attention because universities home and abroad are equally confronted with recruitment of more foreign students who have to use their second language to socialize themselves into international academic circumstances.

\section{REFERENCES}

[1] V.Cook, "Effects of the second language on the first," Clevedon; Buffalo: Multilingual Matters, 2003

[2] P. A Duff,. "Problematising academic discourse socialization," Learning Discourses and the Discourses of Learning, edited by $\mathrm{H}$. Marriott, T.Moore and R.Spence-Brown, 2007

[3] N. Morita, M. Kobayashi. M. "Forthcoming. Academic discourse socialization in a second language," Language Socialization: Encyclopedia of Language and Education, vol. 8. edited by P. Duff, Hornberger, N. Boston: Springer, 2008

[4] N. Morita, " Negotiating participation and identity in second language academic communities,” TESOL Quarterly 38, pp. 573-603, 2004

[5] P. A. Duff, "Problematising academic discourse socialization," Learning Discourses and the Discourses of Learning," edited by $\mathrm{H}$. Marriott, T. Moore and R. Spence-Brown, 2007

[6] P. Duff, "New directions in second language socialization research," Korean Journal of English Language and Linguistics, vol. 3, pp. 309339, 2003

[7] N. Morita, “ Negotiating participation and identity in second language academic communities,” TESOL Quarterly vol. 38, pp. 573-603, 2004

[8] S. Zappa-Hollman, "Academic presentations across post-secondary contexts: The discourse socialization of non-native English speakers,” Canadian Modern Language, 2007

[9] N. Morita, "Negotiating participation and identity in second language academic communities,” TESOL Quarterly vol.38, pp. 573-603, 2004

[10] S. Zappa-Hollman, "Academic presentations across post-secondary contexts: The discourse socialization of non-native English speakers,” Canadian Modern Language, 2007

[11] B. B. Schieffelin, and E. Ochs, "The microgenesis of competence: methodology in language socialization,” In D. I. Slobin, J. Gerhardt, A. Kyratzis, \& J. Guo (Eds.), Social interaction, social context, and language, Mahwah, NJ: Lawrence Erlbaum, 1996, pp.251-263,

[12] D.G.Dorner and G.E. Gorman, "Information literacy education in Asian developing countries: cultural factors affecting curriculum development and programme delivery,” IFLA Journal, vol. 32, pp. 281-293, 2006

[13] D. G. Dorner and G.E.Gorman,"Information literacy education in Asian developing countries: cultural factors affecting curriculum development and programme delivery,” IFLA Journal, vol. 32, pp. 281-293, 2006

[14] S.Leung, "Language socialization: Themes and advances in research,” Teachers College, Columbia University Working Paper, TESOL \& Applied Linguistics, vol.1, 2005
[15] J. Cutler, "The cross-cultural communication trainer's manual, ” vol. 2. Aldershot: Gower Publishing J. 2005

[16] E. M. Hatch, "Discourse Analysis and second language acquisition," In E. M. Hatch (Ed.), Second language acquisition: A book of readings. Rowley, MA: Newbury House. pp. 401-435, 1978 